\title{
CONCEPT OF START STOP RETROFIT SYSTEM FOR MINING EQUIPMENT (OFF-HIGHWAY)
}

\author{
Filipe A. P. Silva ${ }^{1}$, Lucas Ventura ${ }^{1}$, Thiago A. Malicheski ${ }^{1}$ and Dr. Thomas Junge ${ }^{1}$ \\ ${ }^{1}$ Robert Bosch Ltda \\ E-mails: filipe.silva3@br.bosch.com, lucas.ventura@br.bosch.com, \\ thiago.malicheski@br.bosch.com, thomas.junge@br.bosch.com
}

\begin{abstract}
The start/stop functionality is widely used as a fuel saving solution for on-highway vehicles, being constantly studied and implemented in new series models. The subject of this work is to demonstrate the concept of a start/stop system applied as a retrofit solution for off road vehicles that have high fuel consumption and operate many hours a day. Since there is a difference in the systems of mining equipment and passenger cars, and also big difference on the operation of a mine site and an urban driving cycle, the concept of the system needed to be revisited in order to became coherent to the mining scenario and take into consideration the safety related items. The fuel reduction and $\mathrm{CO} 2$ reduction potential are also considered according to the operational reality of a mine.
\end{abstract}

\section{INTRODUCTION}

The concept of a start/stop application is to switch off the engine when the vehicle is stationary, reducing fuel consumption during engine idle, and restart the engine when the operator wants the vehicle to move again. This concept is currently applied on passenger cars enhancing fuel consumption and reducing engine emissions. Although the start/stop application is becoming a standard for passenger cars, it is not deeply introduced in the commercial vehicles markets. However, the same start/stop concept can be applied for offhighway vehicles.

The main difference between the on-highway and the off-highway is the operation profile of the vehicles. Passenger cars considers the possibility to reduce the fuel consumption on red light and traffic situation, however off-highway (e.g. mining equipment) operation does not present the same scenario. For off-highway operation, fuel reduction possibilities are presented during stationary periods when the driver is waiting on a line for loading or unloading the vehicle. Especially this last scenario is observed on mine operations.

Haul dump trucks, used in mine industry, are designed to transport high quantity of minerals and the process of completely loading or unloading one vehicle might take several minutes. During the period when one vehicle is being loaded, other vehicles are in line waiting to be loaded and are stationary with the engine on idle conditions. This period of idling is the period when the start/stop retrofit system demonstrates to be effective. 


\section{MINING TRUCKS OPERATION CHARACTERISTICS}

For the development of the Start/Stop system, i.e. the definition of requirements needed to develop the system algorithm, it is important to understand the behavior of the operator of the vehicle, and the operation field of the vehicle.

Focusing on a mine operation it is typically observed that the operator usually drives the empty (no payload) vehicle from one starting point to a loading queue, where the driver waits for its turn to have his vehicle loaded. When the loading point is empty, the operator drives his vehicle until the loading position. At the loading position, a shovel loads the vehicle's dump with minerals. After the vehicle is fully loaded, the operator drives the vehicle to the queue of vehicles waiting to unload the minerals on the crusher. When the crusher point is empty, the operator drives his vehicle to the crusher point and unloads the minerals to the crusher by using the vehicle's dumper. After unloading the vehicle, the operator starts again the cycle, driving to a new loading queue.

During the moments of waiting on the loading queue and crusher queue, the vehicle is stationary and the fuel reduction possibility trough start/stop system is given.

According to preliminary measurements performed by the authors of this paper, mining trucks are usually stationary during an average period of $30 \%$ of their total operational time on the operation cycles. Unfortunately, not all of the possible stationary periods lead to a condition for shutting down the engine, since safety issues must be considered. This is the case for periods during loading at the shovel, when it is imperative to maintain the engine running, although the vehicle is stationary. Therefore, if we consider only the queue periods, the average period reduces approximately to $10 \%$ of the total operational time of the equipment. Considering an average of 6.000 hours per year of operation, their engines would operate approximately 600 hours in idle. If we consider a typical engine with a displacement greater than 60 liters, the fuel consumption in idle is approximately 30 liters per hour and the potential for fuel reduction is 18.000 liters of diesel per year per vehicle, or 48 tons of $\mathrm{CO} 2$ per year per vehicle.

\section{START/STOP RETROFIT SYSTEM}

A Start/Stop Retrofit (SSR) system operates similar to the standard start/stop serial solutions, but it is adapted to an already existing vehicle as an additional feature. The retrofit idea is to install SSR components in parallel to the existing vehicle systems components, sensing vehicle signals and acting through interventions to simulate operator's behavior to switch off or switch on the engine.

Figure 1 shows simplified the original vehicle configuration of a mining vehicle with electrical propulsion, while Figure 2 shows the same system enhanced by SSR configuration, i.e. the Start/Stop ControllerErro! Fonte de referência não encontrada.. 


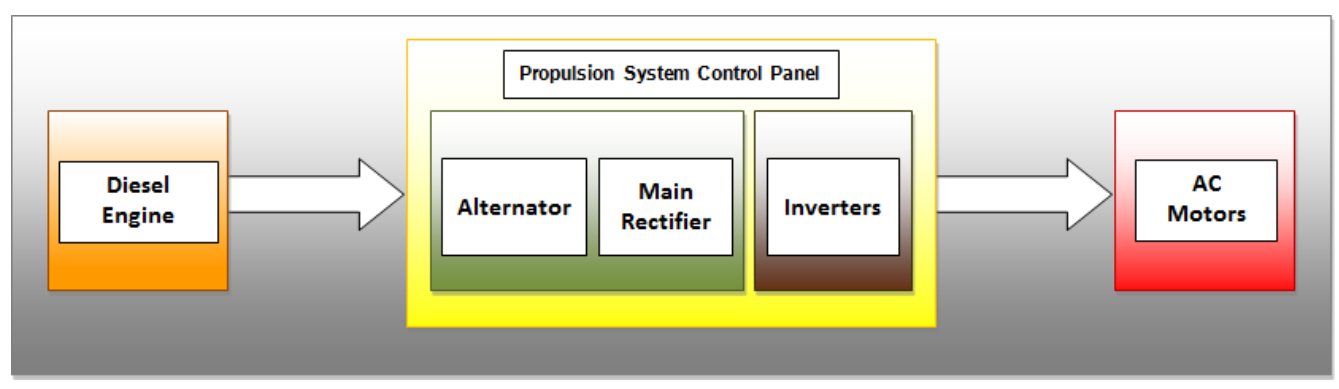

Figure 1 - Original vehicle configuration

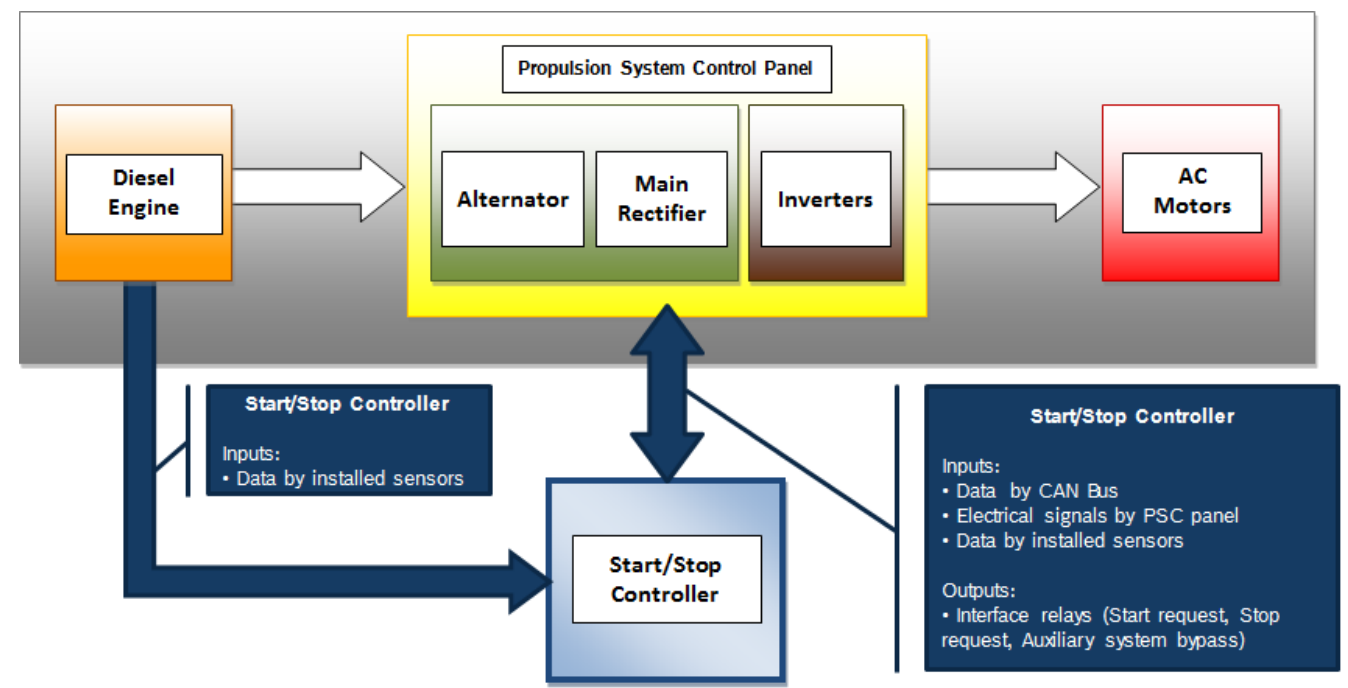

Figure 2 - Retrofit vehicle configuration

The SSR senses the inputs from the vehicle to detect if the engine can be switched off, or to detect if the engine can be restarted. In addition, the SSR outputs controls engine and other necessary vehicle system like horns, parking brake, lock brake and external beacons by means of controlled relays installed on the vehicle's wiring harness.

Input signals are read preferably from the engine/vehicle CAN bus network, where usually most parameters are available (according to SAE J1939 [2] or according to manufacturer provided data). Other parameters are sensed as analog or digital inputs directly from the vehicle wiring harness or by adding new sensors, as long as the intervention does not affect the vehicle' integrity.

\section{START/STOP RETROFIT SYSTEM OPERATION}

For the definition of operating modes and conditions to switch off/on the engine, the initial approach is to analyze the behavior of the operator of the equipment.

Operator behavior analysis demonstrated that the standard operation to stop the vehicle herein defined as "operator stopping procedure" - is executed in the following sequence of actions:

1. Operator takes off foot from accelerator pedal; 
2. Operator brakes the vehicle with the brake pedal in order to stop the vehicle;

3. Operator activates the auxiliary brake system (parking brake or service lock brake) to keep the vehicle stopped;

4. Operator takes off foot from the pedal brake;

5. Operator shifts gear to neutral position.

Operator behavior analysis demonstrated that the standard operation to continue with the vehicle driving after being stationary - herein defined as "operator rerun procedure" - is executed in the following sequence of actions:

1. Operator press the pedal brake;

2. Operator deactivates the auxiliary brake system (parking brake or service lock brake);

3. Operator moves the gear to forward or backward position;

4. Operator takes off foot from the pedal brake;

5. Operator press the accelerator pedal in order to move the vehicle.

From this analysis, it is defined that the vehicle's engine should only be switched off when all the operations of the "operator stopping procedure" have been done. To switch on the vehicle's engine, it is defined that the action of pressing the pedal brake with the engine off should be the trigger for the engine restart.

Figure 3 demonstrates the standard sequence and main conditions for the automatic engine switch off/on.

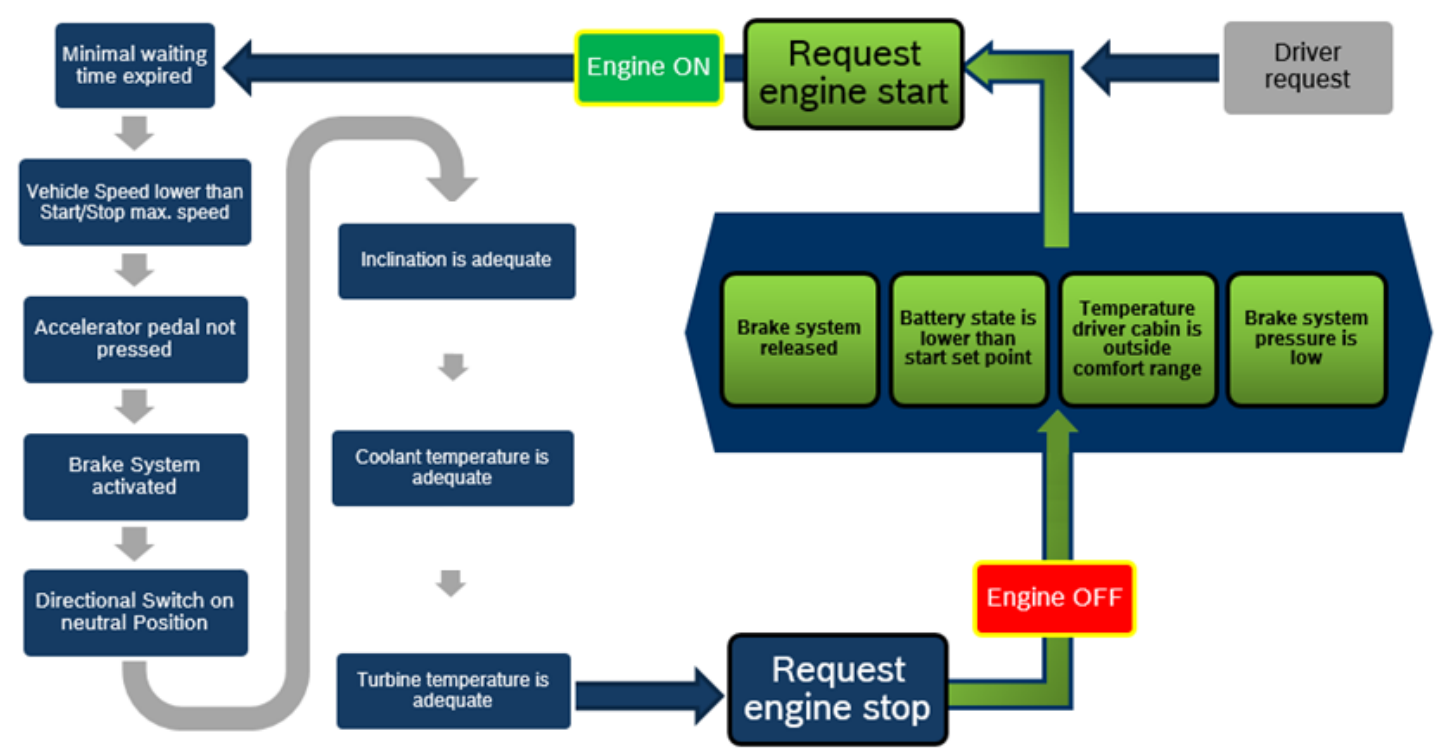

Figure 3 - Start/Stop Retrofit overall shutdown and restart sequence.

\section{MINING TRUCK SYSTEMS AND OPERATION CONSIDERATIONS}

Further study on the vehicle systems demonstrates the need to consider comfort and operational aspects (Table 1). 


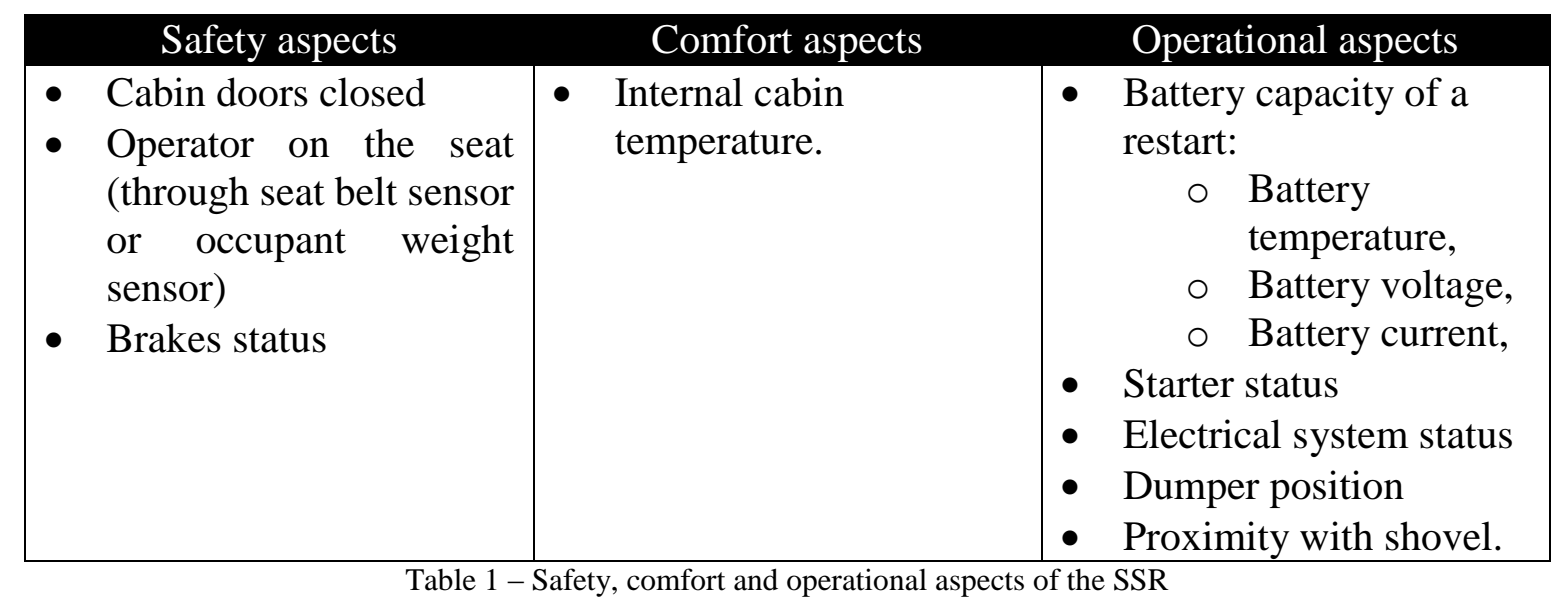

Safety aspects are considered to avoid passenger injury or vehicle damage.

Comfort aspects are considered to guarantee that the system operation will not result in unacceptable comfort condition for the driver. To guarantee the driver's comfort the air conditioning system of the vehicle is essential. Since the air conditioner system of most vehicles operates only when the engine is also operating, the temperature inside the operator cabin need to be monitored by the SSR in order to guarantee that the operator will be able to maintain his comfort inside the cabin. If the temperature of the cabin is out of an acceptable range, the SSR needs to restart the engine.

Operational aspects consider items that can cause an undesired influence in the mine operation. One of the most important topics that Start/Stop systems should be considering is monitoring the capacity of the batteries, in order to sustain several engine starts. Several starts can deplete the batteries, therefore, a future restart by the SSR must be guaranteed. The capacity of the battery is typically monitored by measuring its temperature, instant current and voltage. It is also possible to monitor these parameters by using an Intelligent Battery Sensor (IBS). This information is used to calculate the battery capacity of executing a new restart. Engine starters' status and electrical system's status are monitored to allow a new restart, too. In addition, the operator needs the engine running in order to move the vehicle's dumper, so it is necessary to detect the position of the dumper (down or not down).

Besides the above characteristics, it is also very important not to shut down the engine while loading at the shovel. During loading, the shovel deploys heavy loads of minerals at the vehicles dump. This process results in possible vehicle movements that are strong enough to damage the parking brake. Another important aspect at the shovel is to avoid any restart failures during this operation, i.e. to avoid that a broken-down vehicle would be locking another vehicle's access to the loading point (this scenario would result in loss of production. To avoid this, a proximity detection system between the shovels and the vehicle is necessary. When the shovel and the vehicle are close to each other, the SSR considers that the vehicle is at loading point and disables the engine switch off/on functions.

Regarding the actions (outputs) that the SSR need to execute it is possible to highlight the necessity of triggering a horn sequence for the other operators at the mine be aware that the vehicle will be ready to move. It is also necessary to activate external beacons during the engine stop phase by the SSR, because although the engine is stopped, some vehicle's systems (e.g. hydraulic lines) are activated. 


\section{START/STOP RETROFIT LOGIC}

The main component of the SSR is the Start/Stop Electronic Controller Unit (SSE). All system logics and algorithm are implemented on the SSE. The SSE software controls every intervention performed in vehicle's hardware. The software is developed by using a state machine concept. This state machine works using states and transitions. The states defines which actions will be executed by the SSR. The transitions are responsible check the rules for changing from one to another state. They use input signals and defined conditions to check if they are satisfied or not. Actions are triggered at each reached state.

\section{Start/Stop State Machine}

The state machine (Figure 4) has six main states that coordinates the start/stop operation, which are defined as follows:

- Start State: After the vehicle is first started by the operator, the SSR entry in the Start State. The SSR then awaits all the necessary conditions and actions to happen in order to start the automatic stopping sequence.

- Stop Enable State: This state is reached when the ECU recognize that is possible to activate the start stop function to turn off the engine. Here some safety tests are performed to guarantee a reliable operation. During this state, the SSR activates a parking brake relay, consequently activates the vehicle's parking brake and checks if the parking brake was correctly applied. After activation and check of the parking brake, other hydraulic or pneumatic brakes are inhibited.

- Stopping State: Here the system starts the shutdown process, during this transition phase the ECU checks for the proper actuation of the electrical outputs. During this state, the SSR activates first a dc link bypass relay. This relay disconnects the link between the electrical power system and the diesel engine. After the electrical disconnection, the SSR activates the shutoff relay. The shutoff relay sends a command for the engine ECU to switch off the engine.

- Stop State: With the engine switched off (engine RPM equal to zero) the state machine waits at the stop state until the operator's demand to turn on or any automatic condition forces the start/stop to release the engine cranking. During this state is important to guarantee that essential vehicle systems are operational (e.g. internal/external lamps, horns, radio, etc...). However, usually air condition systems cannot be operational due to the necessity of engine driven compressors (in these cases the internal cabin temperature is be monitored).

- Start Enable State: This state is reached when the ECU recognize that is necessary to activate the start stop function to turn on the engine. Once again, some safety tests are performed to guarantee a reliable operation.

- Starting State: During this state, first the SSR activates the Horn Relay. This relays activates the vehicle's external horn relay to advise the surroundings that the vehicle's engine will be started. After the horn sequence, the SSR activates the SSR start relay. This relay activates the starter relay for a defined period. In normal cases, the engine will reached the necessary speed and is ignited. If the starter is not able to restart the engine, a failure is triggered. 


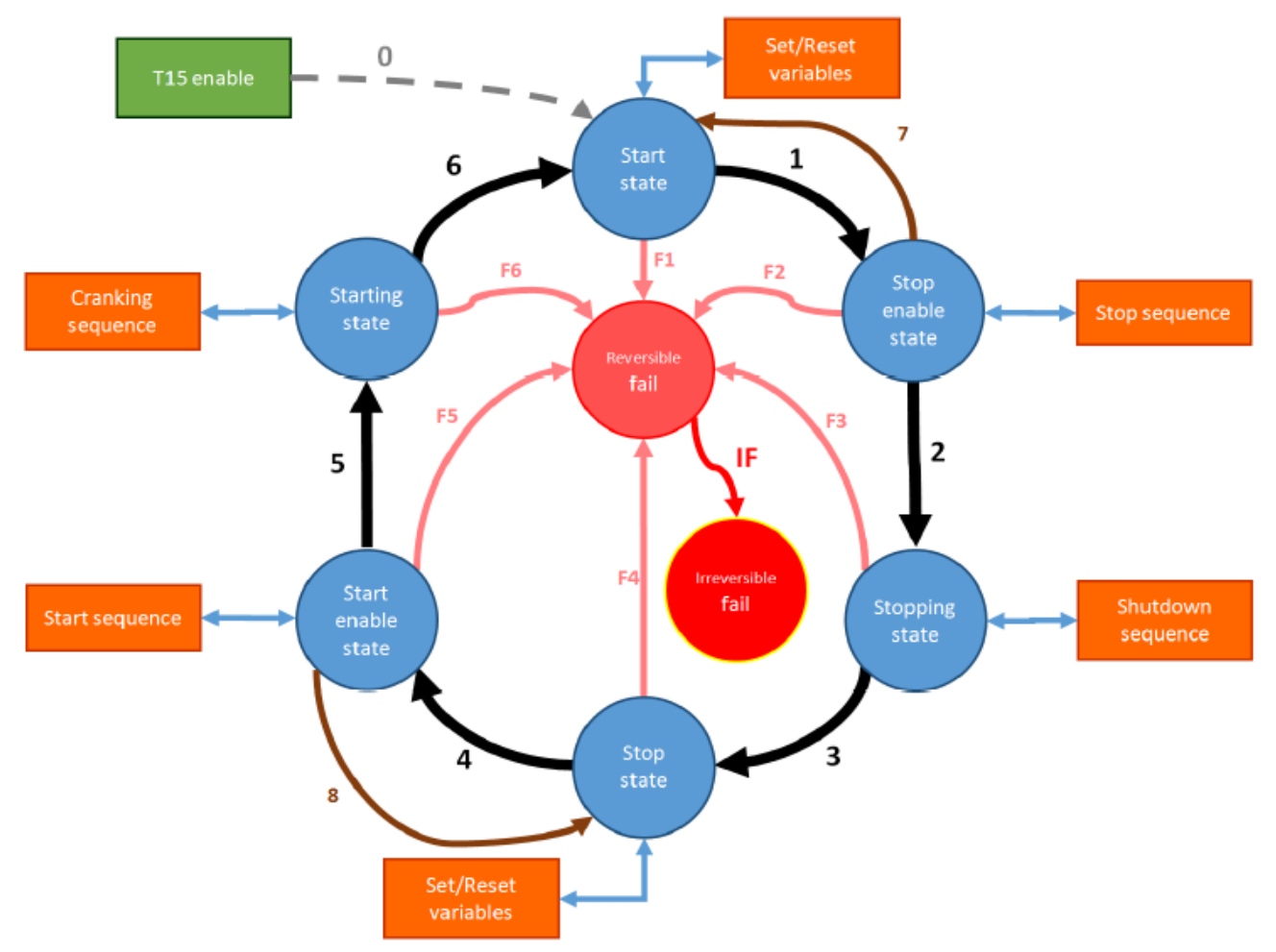

Figure 4 - Start/Stop for mining - State machine

\section{System Transitions}

Transitions between the states are defined depending on the characteristics of each type of vehicle or application (operation characteristics). The software is developed in a way the transitions can be calibrated according to application needs without the need of a new software development.

\section{START/STOP RETROFIT COMPONENTS}

Currently the system is operating as a prototype in a mining application and the main components (Figure 5Erro! Fonte de referência não encontrada.) of the SSR are:

- Main panel box: compartment box composed of the Start/Stop Electronic Controller Unit (SSE) and of several relays to interact with the systems of the equipment.

- Cabin panel box: human machine interface (HMI) containing a switch to turn on/off the SSR, two lamps to indicate system operation and failure, and an emergency switch.

- Battery box: containing temperature, current and voltage sensors to measure the battery condition.

- Data Converter: component to read CAN, RS232 or other communication protocol and translating it to SAE J1939.

- Main wiring harness.

- Proximity RF (radio frequency) Radio and antennas: radio and antennas installed on the equipment and on the shovel to detect distance between both. 
The SSR receives information from the vehicle's systems. The SSE collects all the information, calculates whether some action must be taken, and interfere on the vehicle's electrical system in order to initiate an engine restart or an engine stop.

The interface of the SSE with the vehicle is made by digital communication (CAN-Bus) or by electrical relays. The relays are installed on Relay Box 1 and Relay Box 2 that are part of the Main Box. ECU Box, Relay Box 1 and Relay Box 2 are connected together as the Main Panel Box.

The starting batteries are the main responsible for providing energy for the cranking, so their condition is closely monitored, in order to guarantee that there will be enough energy for the cranking. The battery monitoring is done through the SSR Battery Box, where batteries voltage, current and temperature are measured. Those data are used to calculate the battery conditions in order to define if there will be enough charge for an engine cranking.

In the cabin compartment, accessible to the operator is the SSR Cabin Panel Box, where a cabin temperature is installed and switches and lights are available for the operator.

Besides the three main boxes, a door sensor to detect when the door is open is installed.

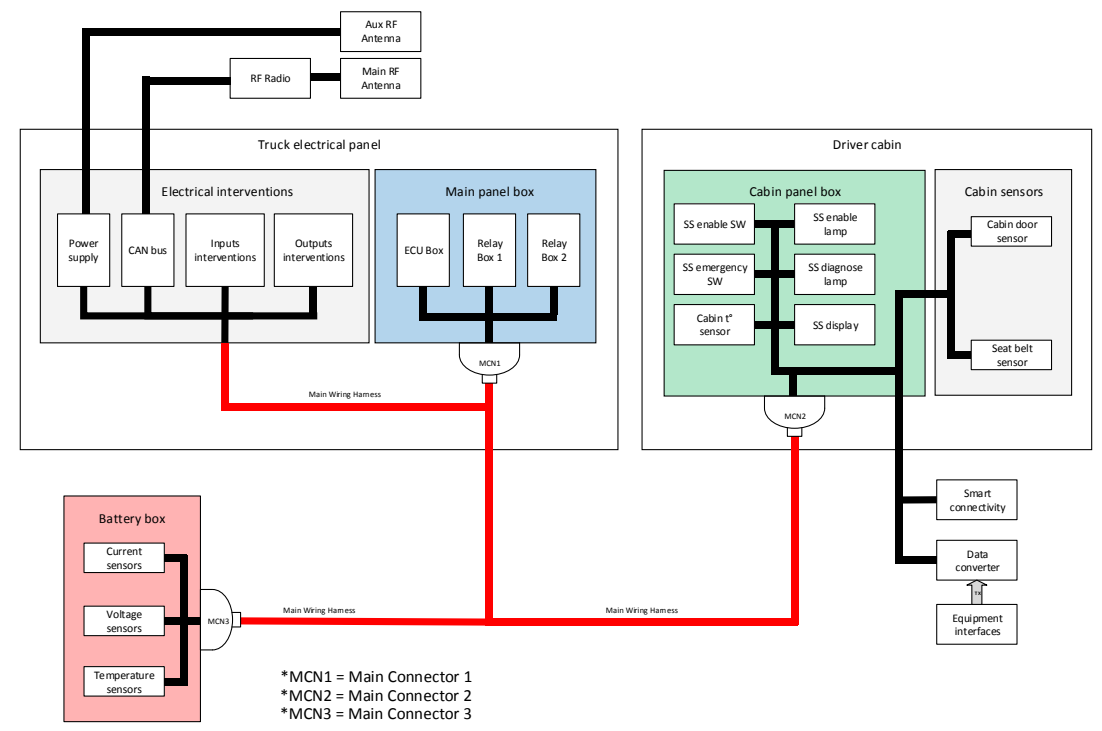

Figure 5 - Start/Stop Retrofit - Components

\section{CONCLUSION}

The availability of a Start/Stop Retrofit systems enables the mine owners to implement the Start/Stop functionality on their fleet equipment, seeking for operational costs reduction due to reduction of fuel consumption. Another important consequence is the direct reduction of $\mathrm{CO} 2$ emissions.

The proposed architecture and concept generates low impact on vehicle systems, with the objective of not affecting the vehicle system operation, the fleet operation, neither the operator behavior.

The state machine approach and the input/output/transition flexibility provides an easy implementation and adaption to different kinds of off-highway vehicles. 
Next steps include testing the SSR on real conditions, and acquiring real-time fuel consumption data along different test vehicles, to be able to determine a mean fuel reduction.

\section{REFERENCES}

[1] Bishop, J., Nedungadi, A., Ostrowski, G., Surampudi, B. et al., "An Engine Start/Stop System for Improved Fuel Economy," SAE Technical Paper 2007-01-1777, 2007, doi:10.4271/2007-01-1777.

[2] SAE J1939 Oct. 2007 Recommended Practice for a Serial Control and Communications Vehicle Network

[3] Harris, Richard. "EN ISO 13849-1 emerging as key global machine safety design standard" isa.org. https://www.isa.org/standards-and-publications/isa-publications/intech-magazine/2012/april/final-say-harris-en-iso13849-1-emerging-as-key-global-machine-safety-design-standard/

[4] Junge, T., A.P. Silva, F., Malicheski, T., "Sistema Retrofit Start\&Stop caracterizado por questões específicas de Safety de Mineração + Start\&Stop com sistema de acionamento(ligar e desligar) de freio (Park) ao desligar e/ou ligar”, Patent Pending BR102015031645-3

[5] Junge, T., A.P. Silva, F., Malicheski, T., Munoz, J., "Start\&Stop com geolocalização para identificação de regiões autorizadas ao funcionamento do sistema a partir do sinal do GPS + Start\&Stop com acionamento a partir do sinal da célula de carga + Start\&Stop com acionamento a partir do sinal do TAG", Patent Pending BR102015031651-8

[6] Junge, T., A.P. Silva, F., Malicheski, T., Munoz, J., "Start\&Stop iniciado com o acionamento do freio", Patent Pending BR102015031641-0 